\title{
Erratum to: Acute and cumulative effects of focused high-frequency vibrations on the endocrine system and muscle strength
}

\author{
Pierpaolo Iodice $\cdot$ Rosa Grazia Bellomo • \\ Glaugo Gialluca $\cdot$ Giorgio Fanò $\cdot$ Raoul Saggini
}

Published online: 26 September 2013

(C) Springer-Verlag Berlin Heidelberg 2013

Erratum to: Eur J Appl Physiol (2011) 111:897-904

DOI 10.1007/s00421-010-1677-2

The reference Pietrangelo et al. 2009 had been inadvertently omitted in the reference section of the original publication. The omitted reference is given below.

Pietrangelo T, Mancinelli R, Toniolo L, Cancellara L, Paoli A, Puglielli C, Iodice P, Doria C, Bosco G, D'Amelio L, di Tano G, Fulle S, Saggini R, Fanò G, Reggiani C (2009) Effects of local vibrations on skeletal muscle trophism in elderly people: mechanical, cellular, and molecular events. Int J Mol Med 24(4):503-512.

The online version of the original article can be found under doi:10.1007/s00421-010-1677-2.

P. Iodice · R. G. Bellomo · G. Gialluca · G. Fanò · R. Saggini

Department of Basic and Applied Medical Sciences,

"G. d'Annunzio" University, Chieti, Italy

e-mail: pierpaolo_iodice@yahoo.it

R. Saggini $(\bowtie)$

Unit of Physical Medicine and Rehabilitation, "G. d'Annunzio"

University, Viale Abruzzo 322, 66013 Chieti, Italy

e-mail:saggini@unich.it 